\title{
THE BENEFITS OF LEADER COMMUNICATION ON PART-TIME WORKER OUTCOMES: A COMPARISON BETWEEN PART-TIME AND FULL-TIME EMPLOYEES USING MOTIVATING LANGUAGE
}

\author{
Jacqueline Mayfield \\ Milton Mayfield \\ Texas A\&M International University \\ Laredo, TX
}

\begin{abstract}
This study presents findings on the differential effects that leader communication has on worker performance and job satisfaction for part-time and full-time workers. For both part-and full-time employees, structural equation model results indicate that leader communication, as measured through motivating language (ML) use, has the same significant and positive effect on job satisfaction. However, in the case of performance, leader $M L$ use only has a significant relationship with the output of full-time workers. These results indicate a boundary condition to the effectiveness of leader communication, and suggest practical implications for management interventions with today's workforce.
\end{abstract}

Today's workforce has experienced dramatic changes in composition and structure during the past few decades, including an increased presence of parttime workers. This form of employment can be quite advantageous to business since it offers staffing arrangements that are more cost-effective and adaptable to economic conditions, can enhance morale, and boost retention of high quality employees who prefer nonstandard work hours (Anonymous, 1996). Recent estimates claim that approximately 16 to $18 \%$ of the U.S. workforce is now comprised of such employees, a substantial increase from 12.1\% in 1957 (Bureau of Labor Statistics, 1998; Stamper \& Van Dyne, 2001; Tilly, 1991). Yet despite this growing reliance on part-time employees, both managers and management researchers know very little about the relevant best practices in motivation. As a result, many of the anticipated cost and performance advantages that have been associated with part-time work may be at risk (Rotchford \& Roberts, 1982; Stamper \& Van Dyne, 2003).

We addressed this knowledge gap by investigating the impact of leader communication on two key motivational markers for part-time employees, job satisfaction and performance. In brief, we compared structural equation model (SEM) results for part-time and full-time employees to determine if there were notable differences between the groups. In the case of part-time employees, the results imply that leader communication significantly enhances job satisfaction, but not 
performance. In contrast, the sample of full-time workers showed significant improvements in both job satisfaction and performance when more positive leader communication practices were observed. These insights and their related implications will be discussed in the following sections: part-time employment trends, leader motivating language-including a model and hypotheses, methods, results, and discussion, which presents recommendations.

\section{Part-Time Employment Trends}

This section gives a short overview of important trends and demographics related to part-time workers including economic factors, definitions, gender, tenure, and status characteristics, variations among subcategories, and motivational research to date. To begin, many economic factors have led to the expansion of part-time employment in the last few decades. Feldman and Doerpinghaus (1992) identified some of these influences as attempts to reduce payroll costs, an economic shift towards $24 / 7$ services, scheduling requirements of labor dependent industries, and just-in-time employment as a response to fluctuating business cycles.

Although part-time employees now constitute almost 20 percent of the U.S. work force, they often coexist or are confounded with other groups of nontraditional workers. Thus, some definitions may be helpful to avoid potential confusion. Part-time employees, technically those persons who work less than thirtyfive hours per week, are often included in the broader category of contingent work, a classification which the Bureau of Labor Statistics also applies to such workers as the self-employed, contract personnel, on-call hires, leased employees, and temp agency workers (FairJobs.org, n.d.; Levenson, 1996; Polivka, 1996). However, unlike many temporary personnel, most part-timers are not engaged in short-term jobs. The majority of part-time employment occurs in the service industries, where such scheduling is an industry standard (McComb, Bourne \& Barringer, 2003; Tilly, 1991).

Other important attributes of part-time workers include demographic factors such as age, gender, and tenure. Not surprisingly, the largest share of part-time workers are women, many of whom find nonstandard employment to be a successful means of balancing work and family life. Furthermore, a substantial number of older persons choose part-time employment. A Bureau of Labor Statistics survey that targeted part-time workers found that $22 \%$ of these employees are over age 55 compared to $15 \%$ of full-time workers within the same age demographic (Anonymous, 1996; Bureau of Labor Statistics, 2005). This growth in the older part-time segment also raises Age Discrimination in Employment Act scrutiny since members of this group should not be unduly placed in part-time positions (AARP, 2006). Similarly important, part-time work is a feasible option for disabled employees and their employers. The percentage of part-time disabled workers grew from $27 \%$ to $33 \%$ between 1984 and 2000 , primarily during the years spanning the Americans with Disabilities Act and its full operationalization, 1990-1994 (Hotchkiss, 2004). 
Despite the permanent structure of most part-time jobs, the national estimated turnover rate for these employees is generally high, with a U.S. average turnover rate in 2002 for part-time workers of $45.9 \%$ compared to $23.8 \%$ for full-time positions. This comparison can also be better understood in light of the pay differential. In 1997, the median hourly wage for part-time employees was only $56 \%$ of their full-time counterparts (Employment Policy Foundation, 2002; King, 2000), roughly equivalent to the same statistic in 1989 (Tilly, 1991). Even more striking, the majority of these workers receive minimal or no benefits. Doerpinghaus and Feldman (1993) found that less than $25 \%$ of these workers are covered by health insurance, and that much smaller percentages are rewarded with other benefits such as life insurance or child care. Similarly, part-time workers often receive less training (thus limiting competence and increasing the accident/injury potential) and fewer promotions. In addition, this same group is offered less protection under employment law, including the Family and Medical Leave Act, than their full-time cohorts (Allan \& Sienko, 1997; Fairjobs.org, n.d,; Rotchford \& Roberts, 1982).

Within this general description, important variances among part-time employees exist that are closely linked to motivation related outcomes. The first such major within-group distinction occurs with voluntary and involuntary part-time employment. The latter classification refers to employees who prefer full-time work, but have been unable to successfully find these positions. (Researchers have posited that the numbers of these persons will fluctuate inversely with labor market demand [Jefferson \& Bohl, 1998]). Over the long term, this respective category accounts for most of part-time employment growth since 1969 (Tilly, 1991). Moreover, the lack of choice associated with these employees has also been linked to such negative organizational citizenship behaviors as being less helpful than their voluntary full-time counterparts (Stamper \& Van Dyne, 2001; 2003).

Another perspective on the overall motivational status of part-time employees is gained in the difference between secondary and retention quality employment. Secondary part-time employment refers to those positions that require few skills, offer low pay and minimal benefits, and are often involuntary; i.e., convenience store employees. These jobs are also characterized by low productivity and high turnover. Conversely, retention quality part-time positions are created to attract highly skilled employees. As a result, these positions offer competitive pay and benefits, are most often voluntary, and are associated with high productivity and low turnover; i.e., an attorney who works 20 hours per week (Cohany, 1997). While retention quality positions represent a minority of part-time employees, their numbers are growing, especially in knowledge management industries, such as information technology (Jefferson \& Bohl, 1998; Leonard, 2000). During the last decade, the Conference Board estimated that part-time professionals accounted for approximately 4.7 million employees representing about twenty percent of 23 million total part-time personnel (Anonymous, 1996). In addition, more recent studies suggest that large employers are offering these workers a richer ar- 
ray of benefit choices including paid leave and some level of health care coverage (Leonard, 2000).

Beyond these configurations, the motivational territory of the part-time work force remains relatively unexplored. Rotchford and Roberts (1982) observed this knowledge gap and urged researchers to address the problem. In particular, these scholars called for future studies on how management practices and demographic variables might moderate productivity levels and other key outcomes for parttime workers. To fulfill this challenge, a few other behavioral researchers have made valuable contributions towards better understanding this employee group and their motivations. Feldman and Doerpinghaus (1992) discovered striking variance in reward demand among three diverse part-time subgroups, nurses, students, and retail salespeople. While pay was an important factor associated with job satisfaction in all subgroups, retention quality workers (mainly nurses) were more intrinsically motivated by their professional responsibilities and were even willing to trade off some salary for scheduling flexibility. On the other hand, retail employees were more motivated by financial incentives and less enthusiastic about the nature of the work itself. Student workers were also motivated by financial rewards and did not equate their current employment with anticipated, "real" careers after their educational goals were attained.

This emphasis on monetary rewards was also found in a study of part-time workers (students) who, in comparison to full-time employees, reported stronger economic exchange relationships and degrees of perceived organizational support (POS) - the belief that an employee's work is valued by an employer. POS is also predicted to be manifest in a worker's increased commitment to her/his employer (Gakovic \& Tetrick, 2003). In comparison, and as previously noted, Stamper and Van Dyne $(2001 ; 2003)$ observed that part-time employees displayed fewer helping behaviors when compared with full-time workers. This line of research has also focused on leadership abilities as potential means to improve part-time employee affect and outcomes, including performance and retention.

Among these interventions, managerial communication has been prominently cited. Skinner (1999) surveyed both management and part-time staffers and found consensus that communication deficiencies - specifically, information sharing and training - ranked among the major disadvantages of part-time work. Feldman and Doerpinghaus (1992) concurred and recommended that part-time employers enhance informational communications and on-the-job training for their staffs. Furthermore, the role of managerial communication in the form of realistic job previews (RJPs; i.e., a pre-hire job description that includes the inherent disadvantages of a particular opening), has long been identified as an effective preemptive measure that reduces negative attitudes and behavioral outcomes in the full-time workforce. This form of information sharing might also have a similar positive impact on part-timers. (Feldman \& Doerpinghaus, 1992). In addition to advocating RJPs as an effective tool for managing the altered psychological contracts that have emerged with the changed structure of contemporary work, Sims (1994) also advised HR professionals to train management in employee commu- 
nication skills. "Today's psychological contract requires an emphasis on talking with people, not at people" (Sims, p. 378, 1994).

\section{Leadership Motivating Language}

Motivating language theory (Sullivan, 1988) predicts that intentional uses of leader speech can significantly enhance such critical employee attitudes and outcomes as job satisfaction, performance, and innovation (Mayfield, Mayfield \& Kopf, 1998; Mayfield \& Mayfield, 2004). More specifically, this theory was conceptualized by Sullivan (1988) to combine the basic linguistics of managerial communication, designated by three core speech acts (Searle, 1969), to stimulate employee motivation, which will be subsequently expressed in worker behaviors that promote organizational goals.

These three forms of speech acts are the following:

1) Direction-giving (perlocutionary) language occurs when leaders clarify goals for subordinates and alleviate organizational uncertainty in the process. For example, a manager displays direction-giving language when she helps a subordinate prioritize the importance of each project within multiple assignments.

2) Empathetic (illocutionary) language is expressed when leaders speak with emotional understanding to subordinates. A manager employs empathetic language when he offers enthusiasm or encouragement to a direct report.

3) Meaning-making (locutionary) language happens when a leader transmits the rules of a particular organizational culture to a subordinate. For instance, a manager uses meaning-making speech when s/he gives a subordinate political suggestions for obtaining corporate buy-in on a project. Cooke and Rousseau (1988) observed that meaning-making language often is delivered indirectly in the form of stories, organizational folklore, and metaphors.

The third component of the motivating language (ML) model, meaning-making language, is expected to serve as a major guidepost in the navigation of organizational change and cultural orientation. This form of talk also distinguishes ML from most well-known leadership communication paradigms which tend to emphasize the two factors of task elucidation and compassion. Transformational leadership theory is an exception here since cultural transmission is one of its important hallmarks (Avolio, Bass \& Jung, 1999; Bass, 1985; Robbins, 2003; Spreitzer \& Quinn, 1996).

Still, in many other ways, motivating language is well-steeped in predominant modern leadership theories. The more recent streams of research have focused on the relevance of leader communications in the nurture and maintenance of organizational commitment and trust (Conger, 1991; Fritz, 1999; Goleman, Boyzatis \& McKee, 2001; 2002; Reina \& Reina, 1999). Equally important, most of these models incorporate managerial communication behaviors as channels between 
leadership goals and their requisite influence on others. For example, showing the connection between employee performance and rewards are core elements of major leadership theories, including the University of Michigan, LMX, PathGoal, Transformational, Primal, Expectancy, and Ohio State schools (Goleman, Boyzatis \& McKee, 2001; Robbins, 2003; Yukl, 1989).

Motivating language is also firmly rooted in three primary assumptions. First, ML pertains only to one sender and message direction, leader-to- subordinate. Secondly, ML embodies the three basic speech acts from the science of linguistics (Searle, 1969; Sullivan, 1988). As a result, the theory is applicable to most forms of leader-to-subordinate speech. Thirdly, the positive employee attitudes and behaviors that are linked with use of motivating language will be much more likely to occur when all three forms of ML are integrated strategically into leader communication. This assumption has also been borne out by previous research that found significant and positive relationships between employee outcomes and multiple types of managerial messages (Petit, Goris \& Vaught, 1997; Sullivan, 1988).

Motivating language has received promising research support as a valuable technique to improve employee attitudes and behaviors. The three components of ML have been adopted into a scale with reliabilities and validity that were strongly corroborated (Mayfield, Mayfield \& Kopf, 1995). Subsequent research has identified ML's positive influence on employee job satisfaction, performance, and innovation. These outcomes can be expected to increase by $7 \%, 2 \%$, and $2 \%$, respectively when a leader uses an extra $10 \%$ of ML in her/his communication practices with direct reports (Mayfield, Mayfield \& Kopf, 1998; Mayfield \& Mayfield, 2004).

These early findings encourage further research into motivating language's capacity to positively impact part-time worker performance. Another helpful insight will come from examining the influence of ML on the job satisfaction levels of part-time workers. The management literature has found significant and positive links between job satisfaction and such critical employee behaviors as absenteeism (Hackett \& Guion, 1985; McShane, 1984; Scott \& Taylor, 1985; Robbins, 2003) and turnover (Hom \& Griffeth, 1995; Griffeth, Hom \& Gaertner, 2000; Robbins, 2003), both of which have important cost implications for an organization's bottom-line (Cascio, 1998; 2000; Robbins, 2003).

To guide this study, the following hypotheses will be tested:

Hypothesis 1: Leader motivating language use is expected to be signifcantly and positively related to full-time worker performance.

Hypothesis 2: Leader motivating language use is expected to be signifcantly and positively related to full-time worker job satisfaction.

Hypothesis 3: Leader motivating language use is expected to be signifcantly and positively related to part-time worker performance. 
Hypothesis 4: Leader motivating language use is expected to be significantly and positively related to part-time worker job satisfaction.

Hypothesis 5: The strength of the relationship between motivating language use and worker performance will significantly differ for part-time and full-time workers.

Hypothesis 6: The strength of the relationship between motivating language use and worker job satisfaction will significantly differ for parttime and full-time workers.

Please note that hypotheses 5 and 6 are stated as alternative hypotheses for congruence with the first 4 hypotheses, and to present these premises in a testable format. Theory from the previous literature review indicates similar results for both full-time and part-time workers. These hypotheses will be evaluated by a corresponding structural equation model in the next section.

\section{Method}

\section{Participants}

Study respondents were canvassed in two phases from different groups to provide a mix of full-time and part-time employees. First phase respondents came from graduate and undergraduate management courses at a medium sized university located in the southwestern United States. The university's student body contains a large number of non-traditional students who either hold full-time work positions or who have returned to campus with substantial work experience. Participation was voluntary, and survey completion did not effect student grades. Students who did complete the survey were provided feedback on survey results, and given information on how they could interpret their responses in order to better understand their workplace situations.

Second phase respondents came from members of the Association for Business Communication, and the Decision Sciences Institute. This stage used an online data collection process. Association members were sent an e-mail requesting survey participation, and those choosing to participate were directed to an online survey site. As in the previous data collection phase, these responses were anonymous. The overall participation rate from both phases exceeded $35 \%$ with 326 respondents who were full-time employees, and 121 respondents who were part-time employees.

Sample demographic characteristics showed some differences between the part- and full-time workers. But these differences are not expected to effect the study variable relationships. Full-time workers had spent an average of 2.80 years working with their current boss, and part-time workers had spent an average of 1.75 years. While these periods vary, both sub-samples seem to have shared sufficient time with their respective leaders to establish stable motivating language 
relationships. Similarly, the difference in mean organizational tenure between the groups (an average of 6.34 years for full-time workers, and 1.90 years for parttime workers) is not expected to play an important role in the superior-subordinate communication interactions examined in this study. Differences also appeared for average respondent ages (34.41 for full-timers, and 22.89 for part-timers). However, subordinate age is not expected to effect the ML relationship. The fulltime sample was predominately female $(62 \%)$ while the part-time sample was predominately male $(72 \%)$. As could be expected, the full-time sample group had a higher education level than the part-time sample group. Approximately $39 \%$ of full-time workers held masters degrees or higher, but only $9 \%$ of the part-time group had attained this educational level. Interestingly, a slightly higher proportion of part-time workers held professional or managerial positions ( $49 \%)$ as compared to the full-time workers (32\%). The remaining breakdown of position types is as follows: skilled work - full-time $62 \%$ and part-time $36 \%$; unskilled work - full-time $6 \%$ and part-time $16 \%$.

The central question that these differences raise is their potential effect on the ML communication that the two worker types experience. If such differences exist, then this variance may be a threat to the study's validity. To check for such possible differences, a multivariate analysis of variance test was performed. The three ML facets were used as the dependent variables, and the worker's job status (part-time or full-time) was the independent variable. Analysis results showed no significant differences between the two samples at the 0.05 alpha level. These results indicate that the groups are similar on the variable of interest. Thus, there are no apparent validity issues in comparing the different worker types - any relational differences between $\mathrm{ML}$ and the outcome variables are likely to arise from non-demographic factors.

\section{Measures}

Study variables were measured using three scales. Leader motivating language use was evaluated by the motivating language scale (Mayfield, Mayfield \& Kopf, 1995). The instrument's reliability, validity, and generalizability have been tested and well-supported in a number of investigations (Mayfield, Mayfield \& Kopf, $1995 ; 1998)$. The ML components were measured through separate sub-scales, and each sub-scale demonstrated a reliability of 0.92 or better in this sample (Churchill, 1979). Worker job satisfaction was gauged using the Hoppock job satisfaction scale (Hoppock, 1935).

Worker performance was assessed through a modified version of the Mott group performance scale (Mott, 1972). The original scale has been shown to accurately capture group performance through a self-administered, individually completed questionnaire. This instrument provided the current authors with a good base for developing an individual performance measure. The individual performance scale was created by adapting Mott's original survey so that it captured an individual's performance rather than a team's performance. This adaption was accomplished by changing the focus of each question from team performance to individual per- 
formance. An additional question was added about the respondent's most recent supervisor rating.

As with the ML scale, all dependent variable survey reliabilities (as tested using the current sample group) showed levels appropriate for our analysis. The job satisfaction scale had a Cronbach's alpha score of 0.85 , and the performance measure had a 0.93 reliability score. Scale descriptives are presented in Table 1, and variable correlations are presented in Table 2 . Copies of the motivating language and performance measures are reproduced in Appendix 1.

\section{Table 1}

Scale Descriptives

\begin{tabular}{lccc} 
Measure & Mean & Standard Deviation & Reliability \\
\hline Direction Giving Language & 2.99 & 0.9 & 0.92 \\
Empathetic Language & 3.25 & 1.07 & 0.92 \\
Meaning-Making Language & 2.45 & 0.98 & 0.93 \\
Performance & 3.41 & 0.8 & 0.93 \\
Job Satisfaction & 4.9 & 1.13 & 0.85 \\
\hline
\end{tabular}

Table 2

Variable Correlations for Full- and Part-Time Workers

\begin{tabular}{|c|c|c|c|c|c|}
\hline & $\begin{array}{c}\text { Direction } \\
\text { Giving }\end{array}$ & Empathetic & $\begin{array}{c}\text { Meaning- } \\
\text { Making }\end{array}$ & Performance & $\begin{array}{c}\text { Job } \\
\text { Satisfaction }\end{array}$ \\
\hline Direction Giving & 1.00 & $0.75^{* *}$ & $0.69 * *$ & $0.14^{*}$ & $0.36^{* *}$ \\
\hline Empathetic & $0.67 * *$ & 1.00 & $0.57 * *$ & $0.17^{* *}$ & $0.47^{* *}$ \\
\hline Meaning-Making & $0.67 * *$ & $0.54 * *$ & 1.00 & 0.10 & $0.26^{* *}$ \\
\hline Performance & -0.05 & 0.04 & 0.00 & 1.00 & $0.36^{* *}$ \\
\hline Job Satisfaction & $0.30^{*}$ & $0.49 * *$ & 0.19 & 0.06 & 1.00 \\
\hline
\end{tabular}

Note: Correlations for full-time workers are presented above the diagonal, and correlations for parttime workers are presented below the diagonal. Correlations significant at the 0.05 level are followed by 1 asterisk. Correlations significant at the 0.01 level are followed by 2 asterisks.

\section{Procedures}

The effects of leader ML use on worker outcomes were tested through structural equation modeling (SEM) using the methods outlined by Joreskog and Sorbom (1989). This analysis procedure allows a researcher to examine latent variables and test for relationships between these variables. Latent variables are constructs that are not directly measurable, but whose properties can be estimated through 
other measurable, or manifest, variables (Joreskog, 1993; Shumaker \& Lomax, 1996). An example of a latent variable is a person's intelligence, which cannot be directly measured. For example, intelligence cannot be touched, weighed, felt, or seen. But it can be indirectly assessed through such means as an IQ test. For this study, three latent constructs were measured: leader motivating language use, worker performance, and worker job satisfaction. All factors were captured by the attendant scales previously discussed in the measures section.

In addition to enabling researchers to examine latent constructs through their manifest variables, SEM also provides a way to simultaneously test the latent variable relationships' significance and strength. In addition, this technique gives diagnostic information on the fit between a theoretical construct and an actual data set. Unlike many other inferential statistical methods, testing SEM model quality does not rely on a single overall measure (such as an F-test with regression analysis). Rather, model adequacy is determined by examining a set of statistical tests. The chi-square test is one such adequacy measure, and it is used to specifically check for discrepancies between the proposed model and the data the model should represent. If there are substantial differences between the model and data, then this test will be significant. Therefore, a non-significant result shows evidence that the model does a good job in representing the underlying variable relationships. However, a potential chi-square measure problem is posed by its sensitivity to trivial discrepancies when samples sizes are large. Consequently, the test may be significant even when the data are well represented by the model (Browne \& Cudeck, 1993; Joreskog, 1993; Joreskog \& Sorbom, 1989; Raftery, 1993; Shumaker \& Lomax, 1996).

In recognition of the chi-square test's sensitivity, other methods have been developed that are less effected by trivial model fit discrepancies. One such measure is the ratio of the chi-square statistic to the chi-square test's degrees of freedom. A model's fit with data is generally considered to be good if this ratio is less than 3.0 - regardless of the test's p-value. Another measure of the model's adequacy is the root mean square error average (RMSEA). This statistic is based on the average difference between the original data set's correlation matrix and a correlation matrix reproduced from the proposed model. Lower RMSEA scores indicate a smaller discrepancy between the data and the model, and are generally considered to indicate a good fit when they are below 0.10 (Browne \& Cudeck, 1993; Joreskog, 1993; Joreskog \& Sorbom, 1989; Raftery, 1993; Shumaker \& Lomax, 1996).

Several other measures - collectively known as fit indexes - also exist. These measures all range from 0.00 to 1.00 , with higher numbers indicating a better fit between the model and data. The two most commonly used fit statistics are the Goodness-of-Fit Index (GFI) and the Adjusted-Goodness-of-Fit Index (AGFI). The AGFI is analogous to the adjusted R-squared measure for regression. It is based on the GFI and provides a mechanism for reducing score "inflation" due to over-fitting a model. The GFI measure is considered to be good when it is above 0.95. The AGFI is considered to be good when it is above 0.90 . Other fit indexes 
include the Bentler-Bonnet normed fit index (NFI), the Tucker-Lewis non-normed fit index (NNFI), and the Bentler centralized fit index (CFI). Scores above 0.95 for these measures are considered to be acceptable (Browne \& Cudeck, 1993; Joreskog, 1993; Joreskog \& Sorbom, 1989; Raftery, 1993; Shumaker \& Lomax, 1996).

All of these adequacy measures compare the data and model fit in slightly different ways. As such, no single metric can be considered to be a complete evaluation of the model appropriateness. Rather, several measurement adequacy tests should be considered in deciding the model's ability to represent the underlying variable relationship structure (Browne \& Cudeck, 1993; Joreskog, 1993; Joreskog \& Sorbom, 1989; Raftery, 1993; Shumaker \& Lomax, 1996).

After a model's quality has been established, the usual procedure is to test for the significance and strength of the relationships between the latent variables. However, for this study the question of interest was not simply if there was a significant link between ML use and performance and job satisfaction, but if the strength of these relationships was the same for both full-time and part-time workers. Accordingly, a method for comparing different subject groups was employed. Conceptually for this method, both groups are initially fit using the same model. Next, tests are applied to determine if significant differences exist between the group's variable relationships. More specifically, a SEM analysis is run separately for the groups, and model adequacy and coefficient strength is noted. Then one group is used as a reference group. The variable relationships (path coefficients) of interest in the other group are subsequently set to equal the values from the reference group, and the model for this second group is run again.

If there are no significant differences between the two groups, then comparison tests will show that the second constrained model specification fits the data as well or better than the initial unconstrained model analysis. (The second analysis may fit the data better than the first test because extra-sample information is being used - i.e. path coefficients - in estimating the second model.) If there are significant differences, then the reformulated model will fit worse than the initial model. Such a disparity means that the two groups' variable relationships differ in some important way. If discrepancies are indicated between the two groups, later tests can then determine where the differences occur. These tests are performed by fixing one coefficient of interest at a time and comparing the models as previously described.

In order to implement this comparison technique, structural equation models were created for both full-time and part-time workers. A model was run for each group in order to determine if the proposed model offered a good fit to the data. After the initial models were run, the full-time workers' model was run again with the appropriate coefficients constrained to equal the part-time workers' model coefficients. More concretely, the full-time workers' model had the paths between the independent (ML) and dependent (performance and job satisfaction) variables' paths set to the part-time workers' coefficients. Significant model differences between the original full-time worker analysis and this new analysis would 
indicate that $\mathrm{ML}$ has a divergent effect between full- and part-time workers for one of more outcomes. Upon finding significant differences, each path could be independently constrained to determine where the variance occurred. The fulltime workers' model was chosen for testing due to its larger sample size. A larger sample size gives greater statistical power, and thus a greater likelihood of detecting any significant path coefficient discrepancies.

\section{Results}

Statistics from the initial structural equation models showed a good fit between the proposed model and the data for both full- and part-time workers. The GFI for the full-time worker model was 0.99 , and the AGFI was 0.96 . The scores on all of the other fit indexes were 1.00. The part-time worker model showed similar results. The GFI for this model was 0.97 , and its AGFI was 0.90 . The scores for this model on the other fit indexes were good, with the lowest score being a 0.98 on the Tucker-Lewis NNFI. The chi-square tests for both models showed no significant discrepancy between the models and the data at the 0.05 level. Finally, the RMSEA index for both groups was within the acceptable range for model adequacy. Table 3 provides full information on fit results.

Variable relationships were next examined after model adequacy was established. For full-time workers, SEM path results indicated a significant link between ML and worker performance, and a significant link between ML and job satisfaction. These findings supported hypotheses 1 and 2 . In contrast, hypothesis 3 was not supported. Results showed no significant link between ML and performance for part-time workers. However, as predicted in hypothesis 4 , there is a significant link between ML and part-timer job satisfaction. Figures 1 and 2 present model results graphically. (Note: in both figures arrows point from the latent factors to the manifest variables. This depiction is in keeping with standard model presentation methods. Such a representation indicates that the latent variables cause the changes in their attendant observable measures - the manifest variables are simply reflections of the underlying factors.)

Subsequent constrained model testing showed results similar to the initial fulland part-time model examination. A chi-square comparison indicated that the fully constrained model fit the data worse than the unconstrained model. This finding showed significant differences between full- and part-time workers for at least one of the two outcome variables. Later tests revealed that when the performance path was set to equal the part-time workers' coefficient (and job satisfaction was not fixed), the model fit the data worse than the unconstrained model. This outcome contradicts the theoretical expectations formalized in hypothesis 5, and indicates significant differences between the groups in the ML-performance link. Nonetheless, the model showed a good fit when only the job satisfaction path was constrained to fit the original model; a result that indicates no significant differences in the ML-job satisfaction link for either sub-group. This finding is congruent with the expectation presented in hypothesis 6 . In sum, results imply that leader motivating language use effects full-time and part-time workers' job satisfaction 
similarly, but only significantly effects a full-time worker's performance. Summary and comparison model results are presented in Table 3.

Figure 1

Structural Equation Model Results for Part-Time Workers

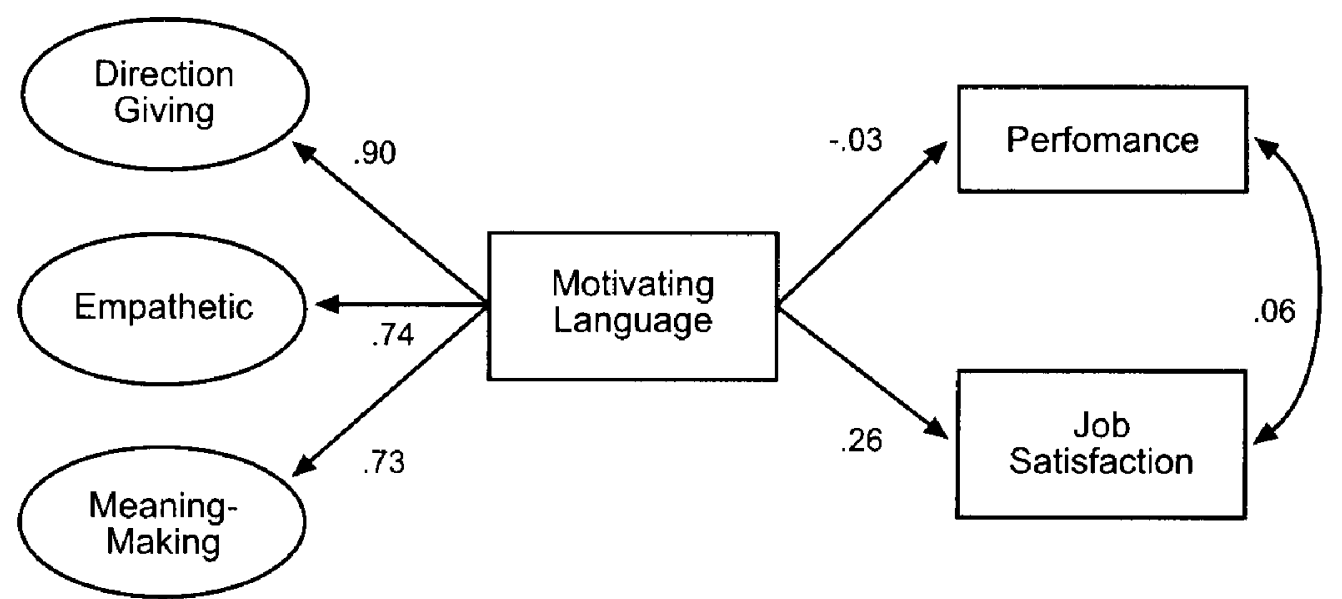

Note: Path coefficients are standardized Figure 2

Structural Equation Model Results for Full-Time Workers

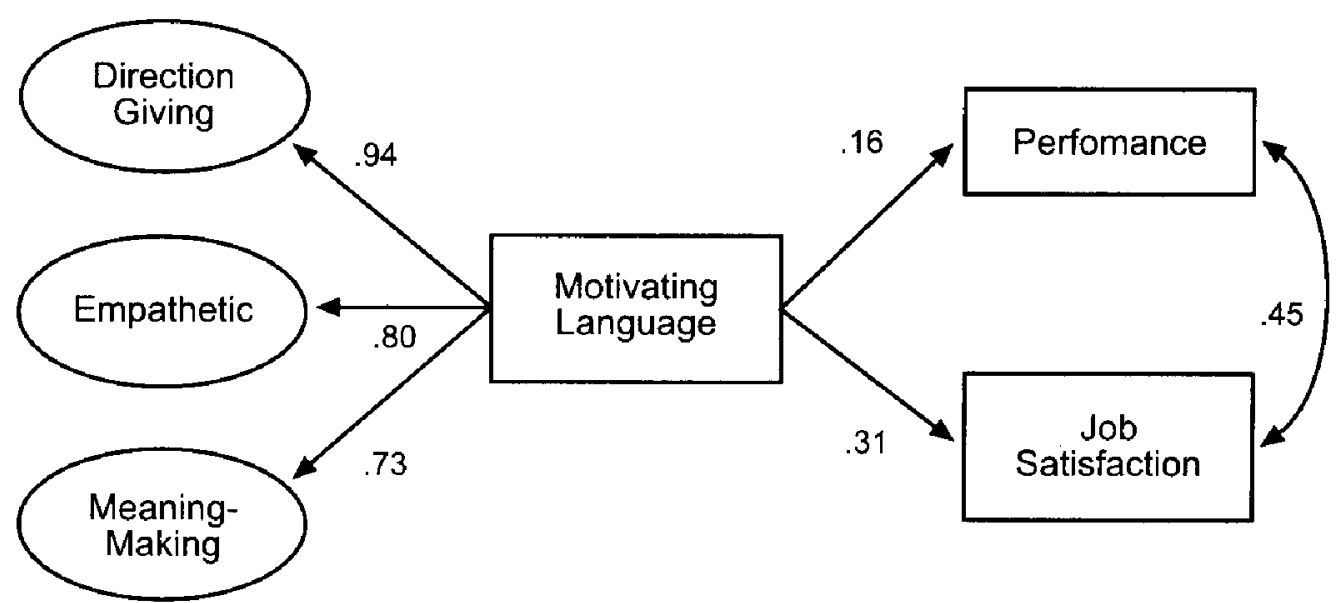

Note: Path coefficients are standardized 
Table 3

Model Analysis Results

\begin{tabular}{|c|c|c|c|c|c|}
\hline & $\begin{array}{l}\text { Full-Time } \\
\text { Workers }\end{array}$ & $\begin{array}{l}\text { Part-Time } \\
\text { Workers }\end{array}$ & $\begin{array}{l}\text { Full-Time: } \\
\text { Both Fixed }\end{array}$ & $\begin{array}{l}\text { Full-Time: } \\
\text { Performance } \\
\text { Fixed }\end{array}$ & $\begin{array}{l}\text { Full-Time: } \\
\text { Job } \\
\text { Satisfaction } \\
\text { Fixed }\end{array}$ \\
\hline GFI & 0.99 & 0.97 & 0.98 & 0.98 & 0.99 \\
\hline AGFI & 0.96 & 0.90 & 0.94 & 0.93 & 0.97 \\
\hline Bentler-Bonnet NFI & 1.00 & 0.99 & 0.99 & 0.99 & 1.00 \\
\hline Tucker-Lewis NNFI & 1.00 & 0.98 & 0.99 & 0.98 & 1.00 \\
\hline Bentler CFI & 1.00 & 1.00 & 1.00 & 1.00 & 1.00 \\
\hline RMSEA & 0.07 & 0.10 & 0.09 & 0.10 & 0.05 \\
\hline $\mathrm{BIC}$ & -20 & -17 & -24 & -17 & -27 \\
\hline $\mathrm{X}^{2}$ Statistic & 9.7 & 8.8 & 20 & 20 & 9.8 \\
\hline $\mathrm{X}^{2}$ d.f. & 4 & 4 & 6 & 5 & 5 \\
\hline $\mathrm{X}^{2} \mathrm{p}$-value & 0.05 & 0.07 & 0.00 & 0.00 & 0.08 \\
\hline $\mathrm{X}^{2} / \mathrm{d} . \mathrm{f}$ & 2.42 & 2.20 & 3.33 & 5.00 & 1.96 \\
\hline \multicolumn{6}{|c|}{$\begin{array}{l}\mathrm{X}^{2} \mathrm{p} \text {-value for } \\
\text { Difference with }\end{array}$} \\
\hline
\end{tabular}

In reference to our hypotheses, propositions 1, 2, 4, and 5 were supported. As previously stated, hypotheses 1 through 4 were formulated to be consistent with developed ML theory. Hypotheses 5 and 6 were worded to aid statistical testing, and proposed counter to theoretical expectations. Therefore, while results from hypotheses $1,2,4$, and 6 were in line with theoretical expectations, results for hypotheses 3 and 5 were not. Table 4 presents a summary of hypothesis results and their meaning for the original theoretical development.

Because hypotheses 3 and 5, relating to the $\mathrm{ML}$ and part-timer performance link, were not congruent with theoretical expectations, a question is raised. Are there differences in the performance measure for full-time and part-time workers? If such differences exist, then it is possible that model discrepancies occur due to some factor other than simple group interaction. To explore this question, two tests were conducted: group performance means were compared through a t-test, and group performance variances were compared through an $\mathrm{F}$-test. Both of these tests returned non-significant results - with a p-value of 0.12 for the t-test, and 0.16 for the F-test. Based on these findings, it seems unlikely that substantial differences exist in the two group's performance levels. 
Table 4

Hypothesis Results

\begin{tabular}{lcc} 
Hypothesis & $\begin{array}{c}\text { Statistical } \\
\text { Result }\end{array}$ & $\begin{array}{c}\text { Theoretical } \\
\text { Implications }\end{array}$ \\
\hline $\begin{array}{l}\text { Hypothesis 1: Leader motivating language use is } \\
\text { expected to be significantly and positively related } \\
\text { to full-time worker performance. }\end{array}$ & $\begin{array}{c}\text { Hypothesis } \\
\text { Supported }\end{array}$ & $\begin{array}{c}\text { Statistical Result } \\
\text { Congruent } \\
\text { with Theoretical } \\
\text { Prediction }\end{array}$ \\
\hline $\begin{array}{l}\text { Hypothesis 2: Leader motivating language use is } \\
\text { expected to be significantly and positively related } \\
\text { to full-time worker job satisfaction. }\end{array}$ & $\begin{array}{c}\text { Hypothesis } \\
\text { Supported }\end{array}$ & $\begin{array}{c}\text { Statistical Result } \\
\text { Congruent } \\
\text { with Theoretical } \\
\text { Prediction }\end{array}$ \\
\hline
\end{tabular}

Hypothesis 3: Leader motivating language use is Hypothesis expected to be significantly and positively related Not Supported to part-time worker performance.
Statistical Result

Not Congruent with Theoretical

Prediction

Statistical

Hypothesis 4: Leader motivating language use is expected to be significantly and positively related to part-time worker job satisfaction.
Hypothesis

Supported
Result Congruent with Theoretical

Prediction

\begin{tabular}{lcc}
$\begin{array}{l}\text { Hypothesis 5: The strength of the relationship } \\
\text { between motivating language use and worker } \\
\text { performance will significantly differ for } \\
\text { part-time and full-time workers. }\end{array}$ & $\begin{array}{c}\text { Hypothesis } \\
\text { Supported }\end{array}$ & $\begin{array}{c}\text { Statistical Result } \\
\text { Not Congruent } \\
\text { with Theoretical } \\
\text { Prediction }\end{array}$ \\
\hline $\begin{array}{l}\text { Hypothesis 6: The strength of the relationship } \\
\text { between motivating language use and worker } \\
\text { job satisfaction will significantly differ for } \\
\text { part-time and full-time workers. }\end{array}$ & $\begin{array}{c}\text { Hypothesis } \\
\text { Not Supported }\end{array}$ & $\begin{array}{c}\text { Statistical Result } \\
\text { Congruent } \\
\text { with Theoretical } \\
\text { Prediction }\end{array}$ \\
\hline
\end{tabular}

\section{Discussion}

The results of our study only partially conformed to expectations. The predictions about ML's positive influence on part-time worker job satisfaction in comparison to full-time employees were supported. Nevertheless, the hypotheses about ML's relationship with part-time employee performance were not sustained. Full-time workers who reported more leader use of ML also scored significantly higher increases in performance than did part-timers who perceived equivalent ML levels.

These results make valuable contributions to both academic researchers and practicing managers. First, this investigation substantiates the relationship be- 
tween strategic leader language and job satisfaction for both full- and part- time employee groups. This disclosure is significant because it replicates previous ML research and sheds new light on the relatively unexplored world of part-time employees' motivation (Allan \& Sienko, 1997). Equally important, many parttime employees hold "front-line" positions that deal with the public in a service capacity. In this context, worker job satisfaction has been closely aligned with customer satisfaction by previous studies (McComb, Bourne \& Barringer, 2003). Furthermore and despite the fact that part-time positions are often created to reduce apparent outlays, there are many "hidden costs" associated with negative job attitudes within this employee group, including turnover and potential litigation under such statutes as the Americans With Disabilities Act and Title IIV of the Civil Rights Act of 1964 (Allan \& Sienko, 1997). Finally, the study also examined the rapport between motivational influences and performance levels for both sets of employees, which responds to the need for improved understanding about the impact that person-environment fit has on job performance (Latham \& Pinder, 2005).

Yet the discrepancies between expected and actual outcomes raise compelling questions and help to shape the directions of future research and new motivational interventions for the part-time work force. First and foremost, why did the parttime and full-time employees express different performance behaviors in response to ML? One possible factor may be demographics. A large number of this study's respondents were also students. As previously discussed, Feldman and Doerpinghaus (1992) found that this subgroup of part-time workers was much more likely to be motivated by financial rewards than their retention quality counterparts. Furthermore, the same authors discovered that the student participants often did not consider their part-time positions as real, "career" jobs. In this perceptual context, talk may be cheap.

These insights point to limitations in this study's research design, particularly regarding the sample group. The participants reported an average age for part-timers of about 23, with an approximate mean of 2 years work experience. Thus, many part-time respondents were relatively young and in the early stages of their work history, possibly reflecting significant experiential bias. Also, while the study was conducted on a heterogeneous sample of organizational members, many respondents had a unique employer. This diversity strengthens generalizability potential, but allows for unrecognized organizational influences. Along the same lines, the observed variance between part-time and full-time employee performance with leader ML use may also be indicative of within group differences that need to be factored into future research and practice. The performance of certain part-time employees; i.e., retention quality employees, may substantially benefit from ML, while the performance of secondary part-time employees may not. Stafford (1998) asserted that many of today's employees exercise "garden variety", namely every day problem-solving, creativity in their jobs and may well be more receptive to extrinsic motivators such as benefits in lieu of managerial communication support for the quality of the work itself. 
Many of these questions can be answered by future research that amends some of the current study's limitations. For example, new investigations could identify possible sources of organizational variance by targeting multiple subjects in multiple organizations. In other words, several organizations could be studied, and several subjects could be sampled within each organization. Then subjects could be coded by respective employer, both facilitating the untangling of organizational and individual variances in the scale and easing the identification of member-organization moderators. In addition, new investigations could draw on a longitudinal design to track perceptions over time, especially through any possible periods of major organizational change. Moreover, the surveys could be revised to better capture demographic characteristics that are associated with divergent subgroups of part-time employees. Also, qualitative feedback on the relationship between ML and key employee outcomes could enrich insights and point the way to revised human resource policy design. Finally, the current investigation's scope could be expanded to explore ML's influence on other key part-time employee behaviors such as absenteeism and turnover.

In conclusion, this study has taken one step towards better understanding a large portion of the U.S. workforce that is relatively obscure. At the same time, the importance of this little known group is growing profoundly for employers due to such societal and industrial factors as increased demand for knowledge-workers, partial retirements, work-family balance, service quality, and the upcoming departure of baby-boomers from today's work place. For all of these reasons, future research on this subject can help both academics (through refined motivational models) and practicing managers (through improved management behaviors and strategic benefit reward system design). The rationale for these steps is clear. This little studied group may harbor many unrealized contributions to organizational goals if appropriate motivational incentives are discovered and incorporated into management practice.

\section{References}

AARP. (2006). Best practices: Avoid age discrimination when offering jobs. Retrieved May 22, 2006 from http:/www.aarp.org/money/careers/employerresourcecenter/ bestpractices.html

Allan, P., \& Sienko, S. (1997). A comparison of contingent and core workers' perceptions of their jobs' characteristics and motivational properties. SAMAdvanced Management Journal, 62, 4-9.

Anonymous (1996). Part-timers becoming permanent fixture in the work force: Survey. Employee Benefit Plan Review, 51, 57-58.

Avolio, B. J., Bass, B. M., \& Jung, D. I. (1999). Re-examining the components of transformational and transactional leadership using the multifactor leadership questionnaire. Journal of Occupational and Organizational Psychology, 72, 441-462. 
Bass, B. M. (1985). Leadership: Good, better, best. Organizational Dynamics, 13, 26-40.

Browne, M. W., \& Cudeck, R. (1993). Alternative ways of assessing model fit. In K. A. Bollen \& J. S. Long (Eds.) Testing structural equation models (pp. 136-162). Beverly Hills, CA: Sage.

Bureau of Labor Statistics. (1998). The employment situation in news release: Selected employment indicators. Retrieved August 12, 2004 from http:/stats.bls.gov/news.release/empsit.t04.htm.

Bureau of Labor Statistics. (2005). Household data annual averages. Retrieved May 10, 2006, from http://www.bls.gov/cps/cpsaat8.pdf.

Cascio, W. F. (1998). Managing human resources: Productivity, quality of work life, profits, 5th ed. New York: Irwin McGraw-Hill.

Cascio, W. (2000). Costing human resources: The financial impact of hehaviors in organizations (4th ed.). Mason, $\mathrm{OH}$ : South-Western College Publishing.

Churchill, G. (1979). A paradigm for developing better measures of marketing constructs. Journal of Marketing Research, 16, 64-73.

Cohany, S. R. (1997). Employment options. Monthly Labor Review, 9, 49-50.

Conger, J. (1991). Inspiring others: The language of leadership. Academy of Management Executive, 1, 31-45.

Cooke, R. A., \& Rousseau, D. (1988). Behavioral norms and expectations: A quantitative assessment of organizational culture. Grotip \& Organizational Studies, 13, 245-273.

Doerpinghaus, H. I., \& Feldman, D. C. (1993). Employee benefit packages for part-time workers. Benefits Quarterly, 9, 72-82.

Employment Policy Foundation (2002, December). Employee turnover - A critical human resource benchmark. hrbenchmarks: Contemporary issues in employment and workplace policy. Retrieved May 15, 2006, from http:/www.epf.org/research/newsletters $/ 2002 / \mathrm{hb20021203.pdf.}$

FairJobs.org (n.d.). Contingent workers fight for fairness: A report from the national alliance for fair employment. Retrieved August 4, 2004, from http://www.fairjobs. org/report/whatis.php.

Feldman, D. C., \& Doerpinghaus, H. I. (1992). Missing persons no longer: Managing part-time workers in the '90s. Organizational Dynamics, 21, 59-72.

Fritz, R. (1999). The path of least resistance for managers: Designing organizations to succeed. Berkeley, CA: Berrett-Koehler Publishers. 
Gakovic, A., \& Tetrick, L. E. (2003). Perceived organizational support and work status: A comparison of the employment relationships of part-time and full-time employees attending university classes. Journal of Organizational Behavior, 24, 649-662.

Goleman, D., Boyatzis, R., \& McKee, A. (2001). Primal leadership: The hidden driver of great performance. Harvard Business Review, 79, 42.

Goleman, D., Boyatzis, R., \& McKee, A. (2002). Primal leadership: Realizing the power of emotional intelligence. Cambridge, MA: Harvard Business School Press.

Griffeth, R. W., Hom, P. W., \& Gaertner, S. (2000). A meta-analysis of antecedents and correlates of employee turnover: Update, moderator tests, and research implications for the next millennium. Journal of Management, 26, 463-488.

Hackett, R. D., \& Guion, R. M. (1985). A reevaluation of the absenteeism-job satisfaction relationship. Organizational Behavior and Human Decision Processes, 35 , 340-382.

Hom, W., \& Griffeth, R. W. (1995). Employee turnover. Mason, OH: South-Western College Publishing.

Hoppock, R. (1935). Job satisfaction. New York: Harper Row.

Hotchkiss, J. L. (2004). Growing part-time employment among workers with disabilities: Marginalization or opportunity? Economic Review - Federal Reserve Bank of Atlanta, 89, 25-40.

Jefferson, F., \& Bohl, D. (1998). CBR minisurvey: Part-time and temporary employees demand better pay and more benefits. Compensation and Benefits Review, 30, 20-24.

Joreskog, K. G. (1993). Testing structural equation models. In K. A. Bollen \& J. S. Long (Eds.) Testing Structural Equation Models (pp. 294-316). Berkeley, CA: Sage.

Joreskog, K. G., \& Sorbom, D. (1989). LISREL 7: A guide to the program and applications, 2nd ed. Chicago: SPSS, Inc.

King, J. E. (2000). Part-time workers' earnings: Some comparisons. Compensation and Working Conditions, summer, 27-36.

Latham, G. P., \& Pinder, C. C. (2005). Work motivation theory and research at the dawn of the twenty-first century. Annual Review of Psychology, 56, 485-516.

Leonard, B. (2000). Recipes for part-time benefits. HRMagazine, 45, 56-60.

Levenson, A. R. (1996). Recent trends in part-time employment. Contemporary Economic Policy, 14, 78-89. 
Mayfield, J., Mayfield, M., \& Kopf, J. (1995). Motivating language: Exploring theory with scale development. Journal of Business Communication, 32, 329-344.

Mayfield, J. R., Mayfield, M. R., \& Kopf, J. (1998). The effects of leader motivating language on subordinate performance and satisfaction. Human Resource Management, 37, 235-248.

Mayfield, M., \& Mayfield, J. (2004). The effects of leader communication on worker innovation. American Business Review, 22, 46-51.

McComb, S. A., Bourne, K. A., \& Barringer, M. W. (2003). Reconciling the paradox of part-time service work. Organizational Dynamics, 32, 342-356.

McShane, S. L. (1984). Job satisfaction and absenteeism: A meta-analytic re-examination. Canadian Journal of Administrative Science, 1, 61-77.

Mott, P. (1972). The characteristics of effective organizations. New York: Harper \& Row.

Pettit, J. D., Goris, J. R., \& Vaught, B. C. (1997). An examination of organizational communication as a moderator of the relationship between job performance and job satisfaction. The Journal of Business Communication, 34, 81-98.

Polivka, A. E. (1996). Contingent and alternative work arrangement, defined. Monthly Labor Review, 119, 3-9.

Raftery, A. E. (1993). Bayesian model selection in structural equation models. In K. A. Bollen \& J. S. Long (Eds.) Testing structural equation models (pp. 162-180). Berkeley, CA: Sage.

Reina, D. S., \& Reina, M. L. (1999). Trust and betrayal in the workplace. San Francisco: Berrett-Koehler Publishers.

Robbins, S. P. (2003). Organizational behavior, 10th ed. Upper Saddle River, NJ: Prentice Hall.

Rotchford, N. L., \& Roberts, K. H. (1982). Part-time workers as missing persons in organizational research. Academy of Management Review, 7, 228-234.

Scott, K. D., \& Taylor, G. S. (1985). An examination of conflicting findings on the relationship between job satisfaction and absenteeism: A meta-analysis. Academy of Management Journal, 28, 599-612.

Searle, J. R. (1969). Speech acts. London: Syndics of the Cambridge University Press.

Shumaker, R. E., \& Lomax, R. G. (1996). A beginner's guide to structural equation modeling. Mahwah, NJ: Lawrence Erlbaum Associates. 
Sims, R. R. (1994). Human resource management's role in clarifying the new psychological contract. Human Resource Management, 33, 373-382.

Skinner, D. (1999). The reality of equal opportunities: The expectations and experiences of part-time staff and their managers. Personnel Review, 28, 425-433.

Spreitzer, G. M., \& Quinn, R. E. (1996). Empowering middle managers to be transformational leaders. The Journal of Applied Behavioral Science, 32, 237-261.

Stafford, S. P. (1998). Capitalizing on careabouts to facilitate creativity. Creativity and Innovation Management, 7, 159-167.

Stamper, C. L., \& Van Dyne, L. (2001). Work status and organizational citizenship behavior: A field study of restaurant employees. Journal of Organizational Behavior, 22 , 517-521.

Stamper, C. L., \& Van Dyne, L. (2003). Organizational citizenship: A comparison between part-time and full-time service employees. Cornell Hotel and Restaurant Administration Quarterly, 44, 33-42.

Sullivan, J. (1988). Three roles of language in motivation theory. Academy of Management Review, 13, 104-115.

Tilly, C. (1991). Reasons for the continuing growth of part-time employment. Monthly Labor Review, 114, 10-18.

Yukl, G. (1989). Managerial leadership: A review of theory and research. Journal of Management, 15, 251-289.

\section{Appendix 1 \\ Motivating Language Scale}

The examples below show different ways that your boss might talk to you. Please use the following selections to choose the answer that best matches your perceptions, and then place an $\mathrm{X}$ in the bracket beside the appropriate response.

(All survey questions had response options as follows: "Very Little", "A Little", "Some", "A Lot", and "A Whole Lot.")

\section{DIRECTION GIVING/UNCERTAINTY REDUCING LANGUAGE}

1. Gives me useful explanations of what needs to be done in my work.

2. Offers me helpful directions on how to do my job.

3. Provides me with easily understandable instructions about my work.

4. Offers me helpful advice on how to improve my work.

5. Gives me good definitions of what I must do in order to receive rewards.

6. Gives me clear instructions about solving job related problems. 
7. Offers me specific information on how I am evaluated.

8. Provides me with helpful information about forthcoming changes affecting my work.

9. Provides me with helpful information about past changes affecting my work.

10. Shares news with me about organizational achievements and financial status.

\section{EMPATHETIC LANGUAGE}

11. Gives me praise for my good work.

12. Shows me encouragement for my work efforts.

13. Shows concern about my job satisfaction.

14. Expresses his/her support for my professional development.

15. Asks me about my professional well being.

16. Shows trust in me.

\section{MEANING MAKING LANGUAGE}

17. Tells me stories about key events in the organization's past.

18. Gives me useful information that I couldn't get through official channels.

19. Tells me stories about people who are admired in my organization.

20. Tells me stories about people who have worked hard in this organization.

21. Offers me advice about how to behave at the organization's social gatherings.

22. Offers me advice about how to "fit in" with other members of this organization.

23. Tells me stories about people who have been rewarded by this organization.

24. Tells me stories about people who have left this organization.

\section{Individual Performance}

Every worker produces something in his or her work. It may be a "product" or a "service." Please think carefully of the things that you produce in your work and how your performance compares to others in your work group. Please place an $\mathrm{X}$ in the brackets beside the response that best describes your work compared to your colleagues' work.

(All survey questions had response options as follows: "Below Average", "Average", "Above Average", "Far Above Average", and "Excellent.")

(Supervisor's Rating)

1. Which of the following selections best describes how your supervisor rated you on your last formal performance evaluation?

(Production: Quantity) 
2. How does your level of production quantity compare to that of your colleagues' productivity levels?

(Production: Quality)

3. How does the quality of your products or services compare to your colleagues' output?

(Production: Efficiency)

4. How efficiently do you work compared to your colleagues? In other words, how well do you use available resources (money, people, equipment, etc.)? (Adaption: Anticipating Problems and Solving Them Satisfactorily)

5. Compared to your colleagues, how good are you at preventing or minimizing potential work problems before they occur?

(Adaption: Awareness of Potential Solutions)

6. Compared to your colleagues, how effective are you with keeping up with changes that could effect the way you work?

(Adaption: Promptness of Adjustment)

7. How quickly do you adjust to work changes compared to your colleagues? (Adaption: Prevalence of Adjustment)

8. How well would you rate yourself compared to your colleagues in adjusting to new work changes?

(Flexibility)

9. How well do you handle work place emergencies (such as crisis deadlines, unexpected personnel issues, resource allocation problems, etc.) compared to your colleagues?

Jacqueline Mayfield is Associate Professor of Management in the Division of International Business and Technology Studies at Texas A\&M International University. Her research includes leader communication, human resources, and international management. The author has published in numerous journals including Business Horizons, Human Resource Management, and the Journal of Business Communication. She is on the editorial board for the Journal of Business Communication, and earned her Ph.D. in management from the University of Alabama.

Milton Mayfield is Associate Professor of Management in the Division of International Business and Technology Studies at Texas A\&M International University. His research interests include leader communication, organizational mortality, the international comic book industry, and business strategy. He has published in numerous journals including Business Horizons, Human Resource Management, and the Journal of Business Communication. He earned his Ph.D.in management from the University of Alabama.

Special thanks to Mary Rowley for all of her insights on part-time workers. 
